\title{
Clinical chemistry laboratory errors at St. Paul's Hospital Millennium Medical College (SPHMMC), Addis Ababa, Ethiopia
}

\author{
Hirut Tadesse ${ }^{1}$, Kassu Desta ${ }^{2}$, Samuel Kinde ${ }^{2}$, Fatuma Hassen ${ }^{2}$ and Addisu Gize ${ }^{3 *}$
}

\begin{abstract}
Objective: This study was aimed to determine the magnitude of errors in clinical chemistry laboratory tests at different phases of the assay of clinical chemistry laboratory unit.

Results: From the total 1633 clinical chemistry laboratory tests done, overall, 541 (33.1\%) errors occurred which accounts that 392 (72.3\%), 45 (8.3\%), and 104 (19.2\%) were pre analytical, analytical and post analytical phases of errors, respectively. Incomplete clinical data of patient was observed on 1185 (72.6\%) of CLL tests. Name, gender, and age of patients were missed on $8(0.5 \%), 190$ (11.6\%), and 257 (15.7\%) forms of the requests, respectively. The physician's name existed only on 248 (15.2\%) and signature on 1137 (69.6\%) of the request forms. An essential patient data were incomplete, which needs emphasis on awareness creation. Such practice improves laboratory data interpretation and thereby prevent misdiagnose and mistreatment of patients.
\end{abstract}

Keywords: Clinical chemistry laboratory errors, Pre-analytical, Analytical, Post-analytical errors

\section{Introduction}

Analysis of body fluids in clinical chemistry laboratory (CCL) is subjected to a number of interferences that affect the pre analytical and analytical accuracy. The interference arises from exogenous sources like drugs and additives as well as such endogenous sources like lipemia, hemolysis and icteria. The clinical chemistry laboratory unit personnel and clinician should constantly be aware of this factor $[1,2]$.

Some of the procedures performed within the laboratory include verifying laboratory results, feeding them into the laboratory information system, and communicating them to the clinicians in a number of ways in particular, by producing a report and making any necessary oral communications regarding "alert" or panic results. Study of laboratory errors in an India Hospital mentioned earlier reported post analytical errors as higher as $16 \%$ of all laboratory errors $[3,4]$.

\footnotetext{
*Correspondence: konjoaddisu@gmail.com; addisu.gize@sphmmc.edu.et ${ }^{3}$ Department of Microbiology, St. Paul's Hospital Millennium Medical College, Addis Ababa, Ethiopia

Full list of author information is available at the end of the article
}

Evaluation of errors in clinical biochemistry laboratory in New Delhi India showed total error rate of 1.4\%, which had contribution of $77.1 \%$ (pre-analytical), 7.9\% (analytical) and 15\% (post-analytical) [5, 6]. Another study identified 189 laboratory errors, a relative frequency of $0.47 \%$, which makes distribution of mistakes was pre-analytical $68.2 \%$, analytical $13.3 \%$, and post analytical $18.5 \%$ [7-9].

Different studies showed different proportions of rejection specimens; highest in the inpatient services (47.15\%) followed by Emergency Department (ED) and outpatient service with $27.40 \%$ and $25.39 \%$ respectively [10] and $67.4 \%$ pre-analytic errors were recorded in Italy [11]. Measuring CCL related errors are mandatory for the total quality of laboratory information to be more effective for patient management; diagnosis and treatment of disease, clinical monitoring and disease prevention. However, studies are non-existent to get the required information in the study area, or in our country at large. So, the main objective of this study was to assess the magnitude of laboratory errors in clinical chemistry laboratory at St. Paul's Hospital Millennium Medical College, Addis Ababa, Ethiopia.

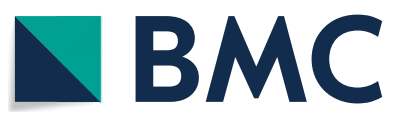

(c) The Author(s) 2018. This article is distributed under the terms of the Creative Commons Attribution 4.0 International License (http://creativecommons.org/licenses/by/4.0/), which permits unrestricted use, distribution, and reproduction in any medium, provided you give appropriate credit to the original author(s) and the source, provide a link to the Creative Commons license, and indicate if changes were made. The Creative Commons Public Domain Dedication waiver (http://creativecommons.org/ publicdomain/zero/1.0/) applies to the data made available in this article, unless otherwise stated. 


\section{Main text \\ Methods}

Cross sectional study design was conducted from December 2015 to March 2016 at St. Paul's Hospital Millennium Medical College (SPHMMC), Addis Ababa, Ethiopia. Many patients are referred from different parts of the country and the hospital performs different services or disciplines as needed, available and serve on the average around 800 patients daily. Blood drawing and sample collections are performed by physicians and nurses from the individual wards and specimens are transported manually by ward staff, laboratory runners and also patient's family to the laboratory.

Firstly, pre-analytical phase's errors include all processes from the time a laboratory request is made by the physician until the sample is ready for testing. The main processes that should be taken into account in the study of the pre-analytical phase are; test selection, patient preparation, collection, transport, handling and preservation of the samples. Secondly, some of the errors in analytical phase include equipment malfunction, sample mix-ups, and interference (endogenous or exogenous) which could be classified into random errors and systematic errors.

Thirdly, in the post-analytical errors phase of the testing process, results are released to the clinician, and she/ he interprets them and makes diagnostic and therapeutic decisions accordingly. In post analytical step, delayed and incorrect results or report those results to whom did not request the laboratory result are the most frequently existed errors.

All clinical chemistry laboratory samples requests were included during the study and requests like blood samples for hematological analysis, stool examination and urinalysis test requests were excluded. Based on the check list, patient socio-demographic information, clinical detail of the patient are collected and observation was made for the presence or absence of hemolysis or sample volume.

Pre-tested check list was used for data collection to increase the quality of data; in addition training was given for data collectors. The data was collected by two trained laboratory technicians during routine and duty hours. The collected data were also checked for completeness by the principal investigator. Data were cleaned and entered into the computer using Excel sheet and exported to SPSS version 20 for analysis. P values less than 0.05 were considered statistically significant.

Ethical approval was obtained from Department of Ethics and Review Committee (DERC), College of Health Science, Addis Ababa University. Based on the approval of the DERC, informed written permission was obtained from St. Paul's Hospital Millennium Medical College
Institutional Review Board (IRB) and submitted to the head of the laboratory department. Informed consent was taken from each participant. Any data generated from the specimens protected the patent privacy, confidentiality and anonymity.

\section{Results}

One thousand six hundred thirty three (1633) clinical chemistry request forms were examined.

From the total figure received in CCL, 828 (50.7\%) of them were female, $622(38 \%)$ of the specimen were male patients and the remaining $183(11.2 \%)$ of the requests gender was not specified. Overall, 541 (33.1\%) errors were found. The highest well documented parameters were the patient identification number of the requests $1633(100 \%)$ and the information about the cite location of requested clinician's, 1615 (98.8\%). Uncompleted patient's laboratory request forms may affect interpretation of test results, the most parameter errors which observed in the study were missing of writing physician's name, $1385(84.8 \%)$ and clinical data of the patient, 1185 (72.6\%) (Table 1).

\section{Pre-analytical, analytical and post-analytical errors}

From the overall, 541 (33.1\%) errors, the contribution of the different phases towards the total number of errors were $72.3 \%$ (pre-analytical), 8.3\% (analytical) and 19.2\% (post-analytical). The most common errors were insufficient blood volume from pre-analytical phase, equipment malfunction from analytical phase and communication errors from post-analytical phases (Table 2).

\begin{tabular}{|c|c|c|c|c|}
\hline Items & $\begin{array}{l}\text { Well written } \\
\text { (n) }\end{array}$ & $\%$ well written & Errors (n) & $\%$ errors \\
\hline $\begin{array}{c}\text { Patient ID } \\
\text { number }\end{array}$ & 1633 & 100 & - & - \\
\hline Patient name & 1625 & 99.5 & 8 & 0.5 \\
\hline Gender & 1376 & 84.3 & 257 & 15.7 \\
\hline Age & 1443 & 88.4 & 190 & 11.6 \\
\hline $\begin{array}{l}\text { Ward/clinic } \\
\text { name }\end{array}$ & 1615 & 98.9 & 18 & 1.1 \\
\hline Physician name & 248 & 15.2 & 1385 & 84.8 \\
\hline Clinical data & 448 & 27.4 & 1185 & 72.6 \\
\hline $\begin{array}{l}\text { Physician } \\
\text { signature }\end{array}$ & 1137 & 69.6 & 496 & 30.4 \\
\hline Correct request & 1387 & 84.9 & 246 & 15.1 \\
\hline Date of request & 1474 & 90.3 & 159 & 9.7 \\
\hline
\end{tabular}


Table 2 Pre-analytical, analytical and post-analytical percent of errors in clinical chemistry laboratory, at SPHMMC, Addis Ababa, Ethiopia, $\mathrm{N}=541$

\begin{tabular}{|c|c|c|c|c|c|}
\hline Pre-analytic phase & $\mathrm{N}(\%)$ & Analytic phase & N (\%) & Post-analytic phase & N (\%) \\
\hline Inadequate sample & $220(40.6)$ & Equipment malfunction & $16(2.95)$ & Communication & $75(14)$ \\
\hline Hemolyzed sample & $124(22.9)$ & QC incompatibility & $16(2.95)$ & Transcription & $6(1.1)$ \\
\hline Lipemic sample & $25(4.6)$ & Reagent expired & $7(1.3)$ & Data entry & $17(3.1)$ \\
\hline Icterus sample & $15(2.8)$ & Reagent contamination & $1(0.2)$ & Sample delay & $4(0.7)$ \\
\hline Over volume & $9(1.7)$ & Reagent storing & $4(0.7)$ & Loss of results & $2(0.4)$ \\
\hline Total & $393(73)$ & Total & $44(8.3)$ & Total & 104 (19) \\
\hline
\end{tabular}

Logistic analysis revealed communication error with laboratory test requested location cite from OPD, and inpatient had significance association. The occurrence of laboratory results not collected by responsible body increased by three times in OPD from others (Table 3).

\section{Discussion}

Across-sectional study conducted in Indian showed, preanalytical errors affecting the laboratory results. No diagnosis was provided on $61.20 \%$ of the laboratory request forms. Type of specimen was not mentioned in $61.60 \%$ of the forms and $89.25 \%$ of all request forms were illegible [12]. Also, in Nigeria, in 2012 their data showed that the mostly omitted information was the patient's age, observed in $48.3 \%$ of request forms reviewed [13].

Laboratory quality is one of the big issues in our context because the laboratory medicine plays a pivotal role in the provision of health care services. In the present study, errors were detected in 542 sample requests, with a total error rate of $33.1 \%$. Out of which the total error pre-analytical (24\%), analytical (2.8\%) and post analytical phases $(6.4 \%)$ which contribute a frequency of $72.3 \%$, $8.3 \%$ and $19.2 \%$, respectively. The computable research done in New Delhi; India [14] with a total error rate of $1.4 \%$, pre analytical, analytical, post analytical phases contributed to $1.1 \%, 0.1 \%$ and $0.2 \%$ of errors respectively as the contribution of the different phases towards the total number of error gave $77.1 \%$ (pre-analytical errors), $7.9 \%$ (analytical errors) and 15\% (post-analytical errors).

From the total of 1633 clinical chemistry laboratory requests, physician name and signatures were missed in $1385(84.8 \%)$ and 469 (30.3\%), respectively. This leads to getting additional information about the patient status, or addressing of laboratory test results the corresponding clinicians show serious drawbacks by the omission of that information. Clinical data not written on the request of 1185 (72.6\%), it was higher frequency as compared to the study of India among 1513 request evaluation of which $61.25 \%$ of the request of clinical data were missed [15], the variation may be attributed high workload and poor documentation in our situation. We found the highest prevalence of errors $72.5 \%$ (393/542) in the pre-analytical phase. Insufficient volume blood sample drawn was the most common error for unsuitable specimen 220 (40.6\%) samples. The next most common cause of error was due to incorrect procedures for hemolysis sample collection

Table 3 The post-analytical Clinical chemistry error the association between communication errors to the location of laboratory request in SPHMMC, Addis Ababa, Ethiopia, N=75

\begin{tabular}{|c|c|c|c|c|c|c|}
\hline \multirow[t]{2}{*}{ Location } & \multicolumn{2}{|c|}{ Communication } & \multirow{2}{*}{$\begin{array}{l}\text { Crude OR } \\
95 \% \mathrm{Cl}\end{array}$} & \multirow[t]{2}{*}{ P value } & \multirow{2}{*}{$\begin{array}{l}\text { Adjusted OR } \\
95 \% \mathrm{Cl}\end{array}$} & \multirow[t]{2}{*}{$P$ value } \\
\hline & Yes & No & & & & \\
\hline \multicolumn{7}{|l|}{ OPD } \\
\hline Yes & 44 & 23 & $0.32(0.11-0.95)$ & 0.027 & $3.10(1.06-9.08)$ & 0.039 \\
\hline No & 31 & 5 & $1: 00$ & & & \\
\hline \multicolumn{7}{|l|}{ Inpatient } \\
\hline Yes & 26 & 2 & $6.63(1.46-30.23)$ & 0.004 & $0.151(0.33-0.68)$ & 0.014 \\
\hline No & 49 & 25 & $1: 00$ & & & \\
\hline \multicolumn{7}{|l|}{ Emergency } \\
\hline Yes & 4 & 3 & $0.45(0.09-2.16)$ & 0.27 & $2.22(0.46-10.63)$ & 0.319 \\
\hline No & 71 & 24 & $1: 00$ & & & \\
\hline
\end{tabular}

OPD outpatient department 
at $124(22.8 \%)$. The result was lower than the Indian study as its indication of common errors of hemolysis was $53.2 \%$ whereas higher lipemia 25 (4.6\%) samples in the current study were observed [14]. These discrepancies may be due to lack of proper orientation of patient's to collect the sample and preparation of sample collectors. In addition the high figure of pre-analytical errors may have partly depended on the fact that most originated from all wards/departments, and not only in the laboratory.

In the current study, 44 errors of events were identified in the analytical phases; which contribute for $8.3 \%$ of the total errors. The most frequently detected analytical problems were due to equipment malfunction 16 (35.6\%) and non-conformity with QC 16 (35.6\%) of the total error frequency. Other sources of analytical errors were reagent expiry 7 (15.6\%), calibration drift 1 (2.2\%) and contamination of reagents 1 (2.2\%). The finding was comparable to the Indian study [14]. From a total 104 (19\%) post-analytical errors; communication errors contribute to $75(72.1 \%)$, data entry errors $17(16.3 \%)$, transcription errors $6(5.8 \%)$, delay sample $4(0.7 \%)$. This total post analytical phase errors also comparable again with the errors observed in India 143 (14.9\%) [14], and communication error contributed to the majority of post analytical errors 75 (14\%).

\section{Conclusion}

In the present study most errors are occurred before samples were analyzed during pre-analytical phase; particularly inadequate sample collection procedure and communication error from OPD department in post analytical phase. This suggests that providing sample collection procedure manual for those who involved in laboratory sample collection and coordination between laboratory and OPD staff workers are the key points for the improvement clinical chemistry laboratory service.

\section{Limitation of the study}

Our study has some limitation like lack of getting similar studies done in Ethiopia, which made difficult for getting more information on the sample size. In the case of some variables; like hemolysis and icterus samples, measurements were made by visual observation which may lead to interpersonal bias, and also we used trained laboratory technician staff as a data collectors which may introduce a social desirability bias.

\section{Abbreviations}

CCL: clinical chemistry laboratory; QC: quality control; SPHMMC: St. Paul's Hospital Millennium Medical College; SPSS: Statistical Package for Social Science.

\section{Authors' contributions}

$A G, H T$ and $F H$ conceived the study, participated in the design, $H T$ and KD involved in data acquisition, and laboratory work. AG, FH and KD made substantial contributions to conception and design. FH and SK drafted the paper. AG critically revised for important intellectual content. All authors read and approved the final manuscript.

\section{Author details \\ ${ }^{1}$ Department of Laboratory Science, St. Paul's Hospital Millennium Medical College, Addis Ababa, Ethiopia. ${ }^{2}$ Department of Medical Laboratory Sciences, School of Allied Health Sciences, College of Health Sciences, Addis Ababa University, Addis Ababa, Ethiopia. ${ }^{3}$ Department of Microbiology, St. Paul's Hospital Millennium Medical College, Addis Ababa, Ethiopia.}

\section{Acknowledgements}

The authors would like to thank staff members of SPHMMC, administration and laboratory staff facilitating the overall research work, particularly during data collection period. We would like to thank Kidest Tesfaye, Director of innovative strategies and operations SPHMMC for her contribution of grammatical and topographical edition of the manuscript.

\section{Competing interests}

The authors declare that they have no competing interests.

\section{Availability of data and materials}

The datasets generated and/or analysed during the current study are not publicly available due to individual privacy but are available from the corresponding author on reasonable request.

\section{Consent for publication}

Not applicable.

\section{Ethics approval and consent to participate}

Ethical approval was obtained from the Department of Ethics and Review Committee, College of Health Science, Addis Ababa University. Informed written permission was obtained from St. Paul's Hospital Millennium Medical College Institutional Review Board (IRB) and submitted to the head of the laboratory department. Verbal informed consent was taken from each participant since the collected data do not contain any individual person's data in any form (including any individual details, images or videos) and any data generated from the specimens protected the patent privacy, confidentiality and anonymity.

\section{Funding}

This study was financially supported by Addis Ababa University (Grant Number 1), Addis Ababa, Ethiopia. The funder had no role in study design, data collection and analysis, decision to publish, or preparation of the manuscript.

\section{Publisher's Note}

Springer Nature remains neutral with regard to jurisdictional claims in published maps and institutional affiliations.

Received: 10 July 2018 Accepted: 27 October 2018

Published online: 03 November 2018

\section{References}

1. Szecsi PB, Ødum L. Error tracking in a clinical biochemistry laboratory. Clin Chem Lab Med. 2009;47(10):1253-7.

2. Sharaki O, Abouzeid A, Hossam N, Elsherif Y, et al. Self-assessment of pre, intra and post analytical errors of urine analysis in clinical chemistry laboratory of Alexandria Main University Hospital. Self. 2014;3(2):96-102.

3. Trivedi P, Shah N, Ramani KV, et al. Managing clinical laboratories: monitor and control lab errors to improve lab performance. Ahmedabad: Indian Institute of Management; 2011.

4. Fryer AA, Smellie WSA. Managing demand for laboratory tests: a laboratory toolkit. J Clin Pathol. 2012;66:62-72.

5. Akan ÖA, Elmali E, Karaeren Z. Evaluation of preanalytic errors in clinical laboratory practice. Lab Med. 2006;37(8):478-80. 
6. Plebani M. Exploring the iceberg of errors in laboratory medicine. Clin Chim Acta. 2009:404(1):16-23.

7. Plebani M, Ceriotti F, Messeri G, Ottomano C, Pansini N, Bonini P. Laboratory network of excellence: enhancing patient safety and service effectiveness. Clin Chem Lab Med. 2006:44(2):150-60.

8. Alagoa PJ, Udoye EP. Laboratory request forms-how well do Doctors fill them? A look at the practice at the Niger Delta University Teaching Hospital, Okolobiri, Bayelsa State, Nigeria. Niger Health J. 2015;15(1):14.

9. Plebani M. Errors in clinical laboratories or errors in laboratory medicine? Clin Chem Lab Med. 2006;44(6):750-9.

10. Stark A, Jones BA, Chapman D, Well K, Krajenta R, Meier FA, et al. Clinical laboratory specimen rejection-association with the site of patient care and patients' characteristics: findings from a single health care organization. Arch Pathol Lab Med. 2007;131(4):588-92.
11. Lippi G, Bassi A, Brocco G, Montagnana M, Salvagno GL, Guidi GC. Preanalytic error tracking in a laboratory medicine department: results of a 1-year experience. Clin Chem. 2006;52(7):1442-3.

12. Chhillar N, Khurana S, Agarwal R, Singh NK. Effect of pre-analytical errors on quality of laboratory medicine at a neuropsychiatry Institute in North India. Indian J Clin Biochem. 2010;26(1):46-9.

13. Oladeinde BH, Omoregie R, Osakue EO, Onifade AA, et al. Evaluation of laboratory request forms for incomplete data at a rural tertiary hospital in Nigeria. N Z J Med Lab Sci. 2012;66(2):39.

14. Goswami B, Singh B, Chawla R, Mallika V. Evaluation of errors in a clinical laboratory: a one-year experience. Clin Chem Lab Med. 2010:48(1):63-6.

15. Chhillar N, Khurana S, Agarwal R, Singh NK. Effect of pre-analytical errors on quality of laboratory medicine at a neuropsychiatry institute in North India. Indian J Clin Biochem. 2011;26(1):46-9.
Ready to submit your research? Choose BMC and benefit from:

- fast, convenient online submission

- thorough peer review by experienced researchers in your field

- rapid publication on acceptance

- support for research data, including large and complex data types

- gold Open Access which fosters wider collaboration and increased citations

- maximum visibility for your research: over $100 \mathrm{M}$ website views per year

At BMC, research is always in progress.

Learn more biomedcentral.com/submissions 